\title{
COMPARISON OF BRUSHLESS EXCITATION AND STATIC EXCITATION SYSTEM LIMITER
}

\author{
Akhilesh Kumar Yadav \\ BE Electrical (Honours) \\ Department of Electrical Maintenance \\ Adani Power Limited, India
}

\begin{abstract}
Whenever generator protection is discussed, the core protection i.e. Generator protection relay is always discussed. No one thought of discussing about generator excitation limiters. Excitation limiters also serve as generator rotor protection. In this paper, excitation system limiters are discussed and also show the comparison between the limiters of two different capacities of generators.
\end{abstract}

Keywords - Limiters, Ie Limiter, P/Q Limiter, V/Hz Limiter

\section{INTRODUCTION}

Excitation system is heart of synchronous generator. To get the rated voltage in the stator of the generator, excitation system provides necessary flux in the rotor. To supply flux in the rotor, excitation system feeds DC current within the rotor. The most function of Excitation system is to perform control and protective functions, which is crucial to the satisfactory operation of the generator.

If excitation system is perfectly designed, which provides

- Reliability in power generation operation

- Stability in power system

- Fast power system disturbance response

Excitation system provides the following protection against.

1. High field voltage

2. High field current

3. High VAR loading

4. Excess flux (volts/Hz)

Above protection achieved by excitation system limiters, which are as follows:

1. Ie or If limiter or over excitation limiter or field winding heating limiter

2. P/Q limiter or under excitation limiter or end winding heating limiter

3. $\mathrm{V} / \mathrm{Hz}$ limiter or over fluxing limiter

4. Ig limiter or stator winding heating limiter

\begin{tabular}{|l|l|}
\hline \multicolumn{2}{|c|}{ COMPARISION OF EXCITATION SYSTEM } \\
\hline Generator - 300 MW & Generator - 660 MW \\
\hline Generator Make - SEC & Generator Make - SEC \\
\hline Brushless Excitation & Static Excitation \\
\hline AVR- ABB Unitrol F & AVR- ABB Unitrol 5000 \\
\hline $\begin{array}{l}\text { Field Forcing- 2 times, 10 } \\
\text { Sec. }\end{array}$ & $\begin{array}{l}\text { Field Forcing- 2 times, 10 } \\
\text { Sec. }\end{array}$ \\
\hline P - 300 MW, Pf-0.85 & P - 660 MW, Pf- 0.85 \\
\hline Ig- 10189 Amp & Ig- 20377 Amp \\
\hline If - 4669 Amp & If - 2510 Amp \\
\hline
\end{tabular}

II. OVER EXCITATION LIMITER (IE) LIMITER

We know that, MVAr is directly proportional to Excitation, \& Excitation is directly proportional to Field current.

The field winding heating will increase, if the field current increases. Hence it is necessary to know the rated field current.

The full load field current is defined as the current required to produce full load stator current at rated voltage, MVA and pf.

OEM allow over excitation of generator for a very short time. When power system disturbance happens, then there occurred a dip in the generator terminal voltage.

To maintain the generator terminal constant, it is required to supply reactive power to the excitation system.

It is required either to supply normal reactive power to the excitation system or to supply beyond the limit, which is totally depend on disturbance level.

When excitation system supply beyond reactive power, then limiter is introduced to monitor whether it is done safely or not.

To insure that generator operated safely in overexcited region during system disturbance, manufacturer provides limiter, called OEL, Ie limiter or If limiter. 
Fig. 1 Brushless Excitation Ie Limiter Setting

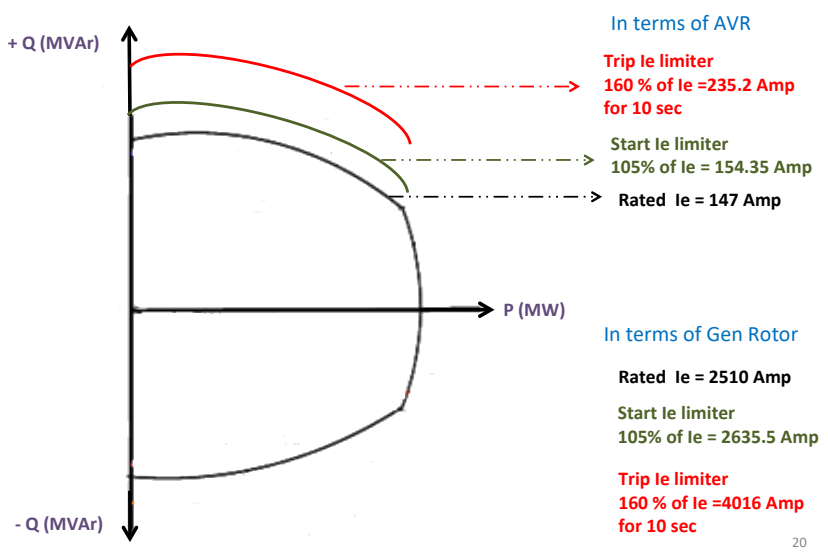

Fig. 2 Static Excitation Ie Limiter Setting.

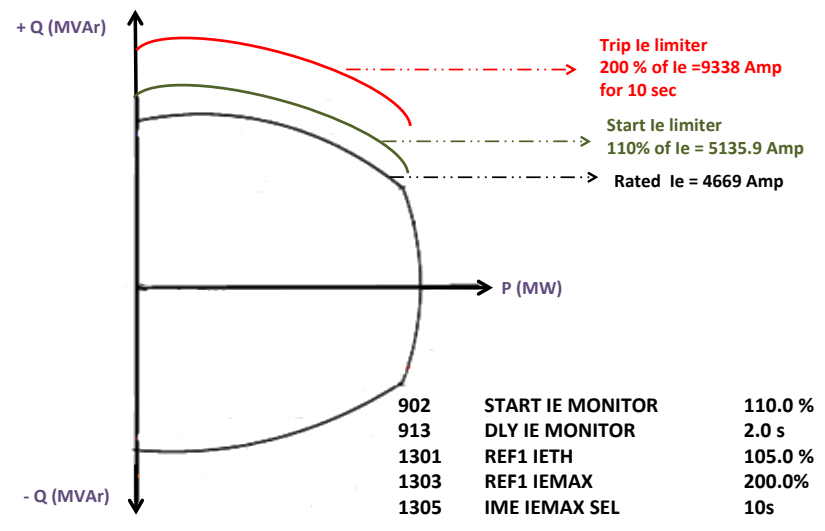

\section{Conclusion-}

After comparing both settings, it is observed that brushless excitation Ie limiter start at $105 \%$ of rated field current and allow maximum field current upto $160 \%$ with time delay of 10sec. but on the other side static excitation Ie limiter starts at $110 \%$ of rated current and allow maximum field current upto $200 \%$ with time delay of $10 \mathrm{sec}$.

i.e Static excitation system time response is faster than brushless excitation system, that can be a reason for higher setting of static excitation Ie limiter.

\section{STATOR CURRENT LIMITER (IG LIMITER)}

In overexcited region, stator current or MVA limit, Limited by stator winding heating limit.

We know that, Steam flow is directly proportional to MW MW is directly proportional to Stator current If stator current increases, stator winding heating will also increases.
This is becoming more issue for machine where the turbine may have uprated and generator has the original design. In this case the increase in generator MW output comes at the expense of available VAR output.

Hence it is necessary to know machine rated MW Output.

Fig. 3 Brushless Excitation Ig Limiter Setting

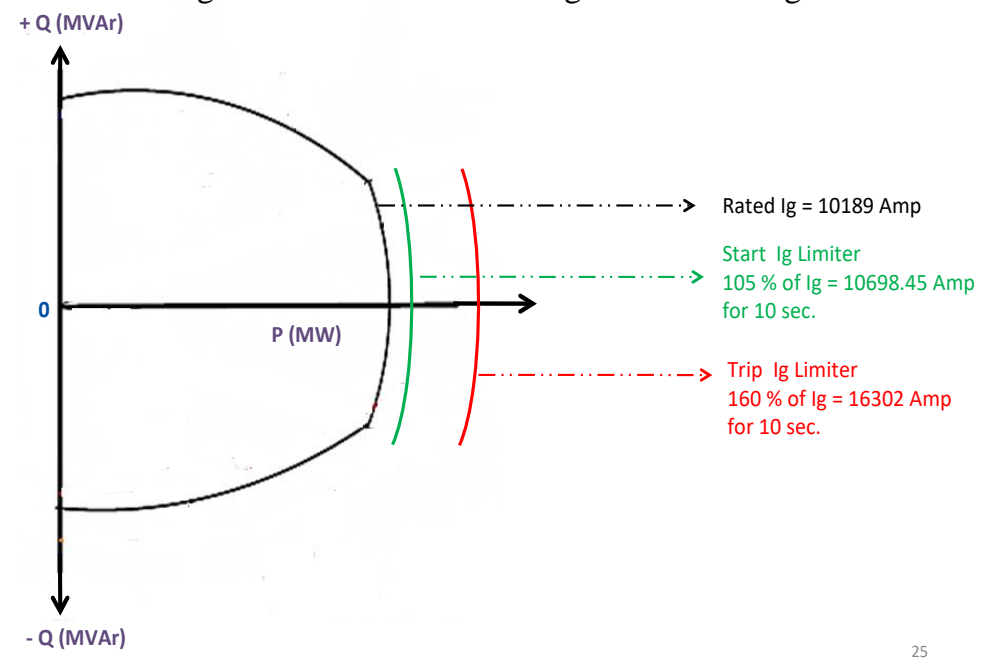

Fig. 4 Static Excitation Ig Limiter Setting.

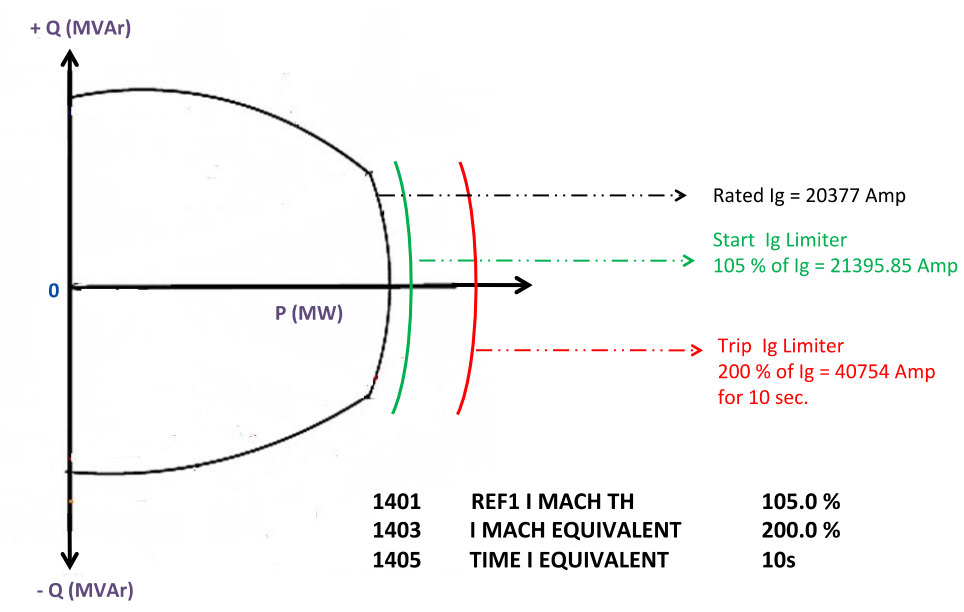

Conclusion-

It is observed that Ig limiter setting is same as Ie limiter setting. As we know that Ig limiter control action depends on the operating point. (MVA). In the overexcited region $(+\mathrm{Q})$ the Ig limiter needs to reduce excitation to bring the operating point down to the limit. Hence again it is depend on AVR response. 


\section{International Journal of Engineering Applied Sciences and Technology, 2020 \\ Vol. 4, Issue 11, ISSN No. 2455-2143, Pages 334-338 \\ Published Online March 2020 in IJEAST (http://www.ijeast.com)}

i.e Static excitation system time response is faster than brushless excitation system, that can be a reason for higher setting of static excitation Ig limiter.

\section{V/Hz LIMITER}

We know that flux of generator,

$$
\varnothing(\mathrm{t})=\mathrm{K}(\mathrm{V} / \mathrm{F}) \operatorname{Cos} \mathrm{wt}
$$

Generators cores are constructed of iron and have the function to carry the magnetic flux of the windings.

They are designed to lead the flux for full load operation without saturation and within the heating limits.

Hysteresis losses and Eddy current cause heating in magnetic material.

During normal operation conditions, all magnetic flux is restricted to the core, as its permeability is much higher than of the adjacent structures.

When the core saturates, the excess of flux spills into the surrounding air space and into non-laminated metallic structures around the core.

These structures are not designed to lead the magnetic flux, and this condition quickly increases the losses and heating which may cause equipment damage.

Table 2 Brushless Excitation V/Hz Limiter Setting

\begin{tabular}{|l|l|l|}
\hline Parameter No. & Description & Setting \\
\hline 912 & START V/HZ MONITOR & $\mathbf{1 0 . 0 \%}$ \\
\hline 913 & DLY V/HZ MONITOR & $\mathbf{2 . 0}$ Sec \\
\hline 1911 & REF V/Hz LIM AVR & $\mathbf{1 1 0 . 0} \%$ \\
\hline 1914 & DELAY V/Hz LIM & 0.0 Sec \\
\hline
\end{tabular}

Condition- 1 when Frequency is constant i.e. $50 \mathrm{~Hz}$

We know that,

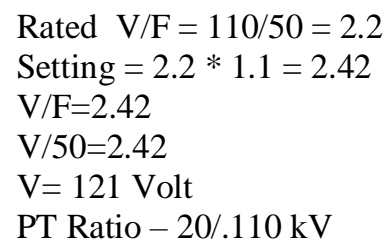

Rated $\mathrm{V} / \mathrm{F}=110 / 50=2.2$

Setting $=2.2 * 1.1=2.42$

$\mathrm{V} / \mathrm{F}=2.42$

$\mathrm{V} / 50=2.42$

$\mathrm{V}=121$ Volt

PT Ratio - 20/.110 kV

Primary side voltage $=22 \mathrm{kV}$

Hence, when frequency is constant, $\mathrm{V} / \mathrm{Hz}$ limiter Start at 22 $\mathrm{kV}$ and $\mathrm{V} / \mathrm{Hz}$ limiter Trip also at $22 \mathrm{kV}$.
If over excitation condition occurred, when frequency is constant, GRP over excitation protection provides backup to AVR over excitation limiter.

Condition- 2 When Voltage is constant i.e. $20 \mathrm{kV}$

We know that,

$$
\begin{aligned}
& \text { Rated } V / F=110 / 50=2.2 \\
& \text { Setting }=2.2 * 1.1=2.42 \\
& V / F=2.42 \\
& 110 / f=2.42 \\
& F=45.45 \mathrm{~Hz}
\end{aligned}
$$

Hence, when voltage is constant, V/Hz limiter Start at 45.45 $\mathrm{Hz}$ and $\mathrm{V} / \mathrm{Hz}$ limiter Trip at $45.45 \mathrm{~Hz}$

If over excitation condition occurred, when voltage is constant, AVR over excitation protection provides backup to GRP under frequency protection.

Table 3 Static Excitation V/Hz Limiter Setting

\begin{tabular}{|l|l|l|}
\hline Parameter No. & Description & Setting \\
\hline 912 & START V/HZ MONITOR & $10.0 \%$ \\
\hline 913 & DLY V/HZ MONITOR & $\mathbf{2 . 0 ~ S e c}$ \\
\hline $1911,1912,1913$ & REF V/Hz LIM AVR & $\mathbf{1 1 0 . 0} \%$ \\
\hline
\end{tabular}

Condition- 1 when Frequency is constant i.e. $50 \mathrm{~Hz}$ We know that,

Rated $\mathrm{V} / \mathrm{F}=110 / 50=2.2$

Setting $=2.2 * 1.1=2.42$

$\mathrm{V} / \mathrm{F}=2.42$

$\mathrm{V} / 50=2.42$

$$
\begin{aligned}
& \mathrm{V}=121 \text { Volt } \\
& \text { PT Ratio }-22 / .110 \mathrm{kV}
\end{aligned}
$$

Primary side voltage $=24.2 \mathrm{kV}$

Hence, when frequency is constant, $\mathrm{V} / \mathrm{Hz}$ limiter Start at 24.2 $\mathrm{kV}$ and $\mathrm{V} / \mathrm{Hz}$ limiter Trip also at $24.2 \mathrm{kV}$.

If over excitation condition occurred, when frequency is constant, GRP over excitation protection provides backup to AVR over excitation limiter.

Condition- 2 When Voltage is constant i.e. $20 \mathrm{kV}$

We know that,

$$
\begin{aligned}
& \text { Rated V/F=110/50=2.2 } \\
& \text { Setting }=2.2 * 1.1=2.42 \\
& \mathrm{~V} / \mathrm{F}=2.42 \\
& 110 / \mathrm{f}=2.42
\end{aligned}
$$




$$
\mathrm{F}=45.45 \mathrm{~Hz}
$$

Hence, when voltage is constant, $\mathrm{V} / \mathrm{Hz}$ limiter Start at 45.45 $\mathrm{Hz}$ and $\mathrm{V} / \mathrm{Hz}$ limiter Trip at $45.45 \mathrm{~Hz}$

If over excitation condition occurred, when voltage is constant, AVR over excitation protection provides backup to GRP under frequency protection..

\section{Conclusion-}

Both excitation systems $\mathrm{V} / \mathrm{Hz}$ limiter setting are same.

\section{UNDER EXCITATION (P/Q) LIMITER}

The bottom region of capability graph is under excitation region. Also referred as leading power factor, where Reactive power is absorbed by machine.

As reactive power draw by machine from grid because of that AVR reduces field current, to maintain the working flux.

Hence it is necessary to know lower limit of filed current. If the field current is less, then

1. Localized heating at end winding

2. Loose SSSL

Fig. 5 Brushless Excitation P/Q Limiter Setting

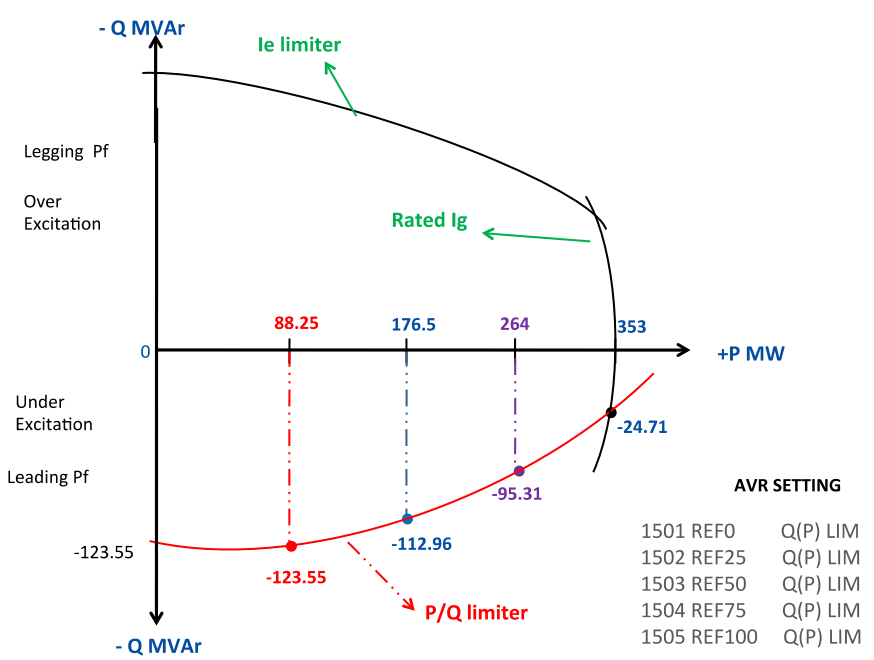

UEL trip setting- $5 \%$

UEL time delay - $2 \mathrm{Sec}$

When excitation current below $5 \%$ of rater field current

Fig. 6 Static Excitation P/Q Limiter Setting



UEL trip setting- $5 \%$

UEL time delay $-2 \mathrm{Sec}$

When excitation current below $5 \%$ of rater field current

\section{Conclusion-}

After comparing both settings it is observed that $\mathrm{P} / \mathrm{Q}$ limiters setting is near about same.

\section{ACKNOWLEDGEMENT}

After comparing all limiters settings of both excitation system, it is found that excitation system limiters play very important role in protection of rotor winding. and limiter setting depends on field forcing design.

Generator can be of any capacitiy and any type of excitation system but excitation limiters setting should be like that Ie limiter

Active -105 or $110 \%$

Trip - 200\% within $10 \mathrm{sec}$

Ig limiter

Active -105 or $110 \%$

Trip - 200\% within $10 \mathrm{sec}$

P/Q Limiter

-35.0 Trip $-5 \%$ within $2 \mathrm{sec}$

$-35.0 \% / \mathrm{Hz}$ limiter

-27.0 Trip -1.1 within $2 \mathrm{sec}$

\section{REFERENCE}

[1] J. R. Ribero. (March 1991). Minimum Excitation Limiter Effects on Generator Response to System Disturbances, IEEE Transactions on Energy Conversion, Vol. 6, No. 1,

[2] IEEE Task Force. (September 1995). Excitation Limiters, Underexcitation Limiter Model for Power System Stability Studies, IEEE Transactions on Energy Conversion, Vol. 10, No. 3, 
[3] S. S. Choy and X. M. Xia, (February 2000). Under Excitation Limiter and Its Role in Preventing Excessive Synchronous Generator Stator End-Core Heating. IEEE Transaction on Power Systems, Vol. 15, No. 1, pp. 95-101,

[4] A.Murdoch, R.W. Delmerico, S.Venkataraman, R.A. Lawson, J.E, Curran, W.R. Pearson, (Dec. 2000) Excitation System Protective Limiters and Their Effect on Volt/var Control - Design, Computer Modeling, and Field Testing IEEE Transactions on Power Delivery, IEEE Transactions on Energy Conversion, Volume: 15, Issue: 4, Pages: $440-450$

[5] IEEE Committee Report. (Oct. 2004). Performance of Generator Protection During Major System Disturbances. IEEE Transactions on Power Delivery. IEEE Transactions on Power Delivery, Vol19,

[6] IEEE Standard. (April 2006) .Guide for AC Generator Protection, C37.102/D7-200X,

[7] Working Group J5 of Power System Relaying Committee, Charles J. Mozina, Chairman, (June 2007). Coordination of Generator Protection With Generator Excitation Control and Generator Capability, IEEE PES General Meeting, Tampa, FL,

[8] G. Benmouyal, (October 2007). The Impact of Synchronous Generators Excitation Supply on Protection and Relays," proceedings of the 34th Annual Western Protective Relay Conference, Spokane, WA,

[9] Guidelines for NERC Compliance. (November 29, 2007) Generator Control Testing to Certify Reactive Power Capability, Excitation System Functions and Frequency Response, , Product Id: 1014911,

[10] G. R. Berube and L. M. Hajagos, (2009). Coordination of Under Excitation Limiters and Loss of Excitation Relays With Generator Capability, IEEE Power \& Energy Society General Meeting, Calgary, AB, , pp.1-8.

[11] User Manual \& Trouble shooting guide for $A B B$ Excitation system Unitrol F \& 5000 Operation. Product ID- 3BHS104765 E80 